\title{
Docência orientada na formação stricto sensu em enfermagem antes e durante a pandemia: relato de experiência
}

\author{
Oriented teaching in stricto sensu training in nursing before and during the pandemic: an
} experience report

Enseñanza guiada en la formación stricto sensu en enfermería antes y durante la pandemia: informe de una experiencia

\begin{abstract}
Resumo
Objetivo: relatar a práxis docente de mestrandos/doutorandos ao realizar as Docências Orientadas desde o ano de 2014 até o ano de 2021, frente as disciplinas de Exercício da Enfermagem A e B contida no Projeto Pedagógico de um Curso de Graduação em Enfermagem antes e durante a pandemia de COVID-19. Método: Trata-se de um relato de experiências de mestrandos e doutorandos do Programa de Pós-Graduação em Enfermagem da Universidade Federal de Santa Maria (UFSM), localizada na região sul do Brasil. São descritas as experiências da práxis docente dos autores desde o ano de 2014 até o ano de 2021, acerca do planejamento e desenvolvimento das disciplinas de Exercício A e B contida no Projeto Pedagógico do Curso de Graduação em Enfermagem da instituição, ministradas por meio da Docência Orientada I e II, antes e durante a pandemia de COVID-19. Resultados: para o desenvolvimento da práxis da docência foram utilizadas diversas metodologias de ensino, de avaliação e materiais didáticos, como: vídeos, filmes, estudos de caso, jogos educativos, portfólios e seminários. No contexto da pandemia, houve a necessidade de adaptar as aulas ao ensino remoto, oportunizando uma experiência ímpar aos discentes stricto sensu. Conclusão: as atividades de docência orientada são essenciais para a formação de docentes, visto que possibilitam ao discente da Pós-Graduação refletir e agir frente ao planejamento e condução de atividades de ensino, bem como as readequações educacionais necessárias com a pandemia da COVID-19.
\end{abstract}

Palavras-chave: Enfermagem; Ensino; Educação em enfermagem; Educação de pós-graduação em enfermagem; COVID-19.

\footnotetext{
Abstract

Objective: To report on the teaching practice of master's/doctoral students in their Guided Teaching Assignments from the year 2014 to the year 2021, facing the discipline of Nursing Practice A and B contained in the Pedagogical Project of an Undergraduate Course in Nursing before and during the pandemic of COVID-19. Method: This is an experience report of master's and doctoral students of the Graduate Nursing Program of the Federal University of Santa Maria
} 
(UFSM), located in southern Brazil. The experiences of the teaching praxis of the authors from the year 2014 to the year 2021 are described, about the planning and development of the subjects of Exercises A and B contained in the Pedagogical Project of the Undergraduate Course in Nursing of the institution, taught through Guided Teaching I and II, before and during the pandemic of COVID-19. Results: for the development of the teaching practice, several teaching and assessment methodologies and didactic materials were used, such as: videos, films, case studies, educational games, portfolios and seminars. In the context of the pandemic, there was a need to adapt the classes to remote teaching, providing a unique experience to stricto sensu students. Conclusion: guided teaching activities are essential for teacher training, as they allow the graduate student to reflect and act upon the planning and conduct of teaching activities, as well as the educational readjustments required with the COVID-19 pandemic.

Keywords: Nursing; Education; Nursing education; Postgraduate in nursing education; COVID-19.

\section{Resumen}

Objetivo: Relatar la práctica docente de los mestrandos/doutorandos en la realización de las Docencias Orientadas desde el año 2014 hasta el año 2021, frente a la disciplina de Ejercicio de la Enfermería A y B contenida en el Proyecto Pedagógico de un Curso de Graduación en Enfermería antes y durante la pandemia de COVID-19. Método: Se trata de un informe de experiencia de estudiantes de maestría y doctorado del Programa de Posgrado en Enfermería de la Universidad Federal de Santa María (UFSM), ubicada en el sur de Brasil. Se describen las experiencias de la praxis docente de las autoras desde el año 2014 hasta el año 2021, sobre la planificación y desarrollo de las asignaturas de Ejercicios A y B contenidas en el Proyecto Pedagógico del Curso de Pregrado en Enfermería de la institución, impartido a través de Docencia Guiada I y II, antes y durante la pandemia de COVID-19. Resultados: para el desarrollo de la práctica docente, se utilizaron diversas metodologías de enseñanza y evaluación y materiales didácticos, tales como: videos, películas, estudios de casos, juegos educativos, portafolios y seminarios. En el contexto de la pandemia, era necesario adaptar las clases a la enseñanza a distancia, proporcionando una experiencia única a los estudiantes stricto sensu. Conclusión: las actividades docentes guiadas son esenciales para la formación del profesorado, ya que permiten al estudiante de posgrado reflexionar y actuar sobre la planificación y realización de actividades docentes, así como sobre los reajustes educativos necesarios con la pandemia del COVID-19.

Palabras clave: Enfermería; Educación; Educación en enfermería; Educación de postgrado en enfermería; COVID19.

\section{Introdução}

No cenário acadêmico, o pensar e fazer dos docentes universitários, nunca esteve tão em evidência quanto nos últimos anos, constituindo-se objeto de diversos questionamentos em especial acerca da prática pedagógica e da integração ensino e pesquisa, que irão articular a práxis profissional diária no mundo contemporâneo (Brehmer \& Ramos, 2014). Os desafios da formação universitária de qualidade crescem proporcionalmente as mudanças nos aspectos social, ético, econômico e político da sociedade pós-moderna, as quais atingem de modo decisivo o ensino superior (Mesquita et al., 2016).

A docência universitária requer formação profissional para seu exercício, esta deve estar fundamentada no domínio de saberes e conhecimentos produzidos cientificamente em um determinado campo disciplinar. A aquisição de conhecimentos e habilidades integradas ao saber ensinar como mediador de aprendizagem junto a sujeitos aprendizes fornece congruência e confere cientificidade epistemológica na prática como referência que integra o binômio teoria/prática, revela também o potencial de criticidade e transformação no perfil do futuro profissional, principalmente quando se defende uma formação integral para além do ensino (Vasconcello, \& Sordi, 2016).

Para atender estas novas perspectivas da prática docente na educação em enfermagem, inserem-se os estágios de docência orientada como oportunidade para habilitar pós-graduandos para uma formação crítica, reflexiva e criativa. A pósgraduação stricto sensu é estruturada com o intuito de permitir o desenvolvimento de profissionais docentes com consciência reflexiva da práxis pedagógica, para melhor qualificação do ensino aprendizagem e possibilita ao discente stricto sensu a autonomia para a realização do seu auto aprendizado (Bastolla et al., 2017).

A docência orientada é uma atividade desenvolvida por discentes de mestrado e doutorado, destacando-se como uma experiência essencial para a formação stricto sensu em enfermagem. Por meio desta, os docentes em formação têm a possibilidade de vivenciar a práxis da docência, possibilitando a compreensão do seu papel na formação profissional. Ainda, esta contribui para a aprendizagem da docência universitária na medida em que auxilia os pós-graduandos stricto sensu a 
identificar os saberes necessários à prática docente e a perceber a sala de aula da graduação como um lugar essencial de formação e identificação com a futura profissão (Leitão et al., 2017).

O exercício da Docência Orientada foi instituído nos Programas de Pós Graduação pela Coordenação de Aperfeiçoamento de Pessoal de Nível Superior (CAPES, 2012), determinando prerrogativas básicas para sua operacionalização. Esta prática é uma atividade curricular para estudantes de cursos de pós-graduação stricto sensu. A docência é parte integrante da formação do mestrando/doutorando, objetivando a preparação para a docência de modo que esteja supervisionada pelo orientador (CAPES, 2012).

Em meio aos diversos desafios que a formação e o ensino enfrentam, no ano de 2020 foram impostas necessidades de adaptação do ensino presencial. No dia 03 de fevereiro de 2020, o Ministério da Saúde (MS) declarou Emergência em Saúde Pública de Importância Nacional (ESPIN) no Brasil, em decorrência da Infecção Humana pelo novo Coronavírus (COVID-19) (Brasil, 2020a). Ao final do mês março de 2020, o MS declarou o estado de transmissão comunitária da COVID-19 em território nacional (Brasil, 2020b). Visto isso, como estratégia para dar continuidade ao ensino no curso de enfermagem, devido a necessidade de isolamento e distanciamento social, o uso das tecnologias digitais, já utilizadas na educação e em outros contextos, foi necessária e fundamental no processo de ensino e aprendizagem neste momento de emergência de saúde pública (Silva et al., 2021). Professores e estudantes reinventaram-se para o enfrentamento desse novo desafio. No entanto, há de se destacar que os momentos de crise propiciam a abertura de novos horizontes (Varella et al., 2020).

Frente ao exposto, este relato objetiva relatar a práxis docente de mestrandos/doutorandos ao realizar as Docências Orientadas desde o ano de 2014 até o ano de 2021, frente as disciplinas de Exercício da Enfermagem A e B contida no Projeto Pedagógico de um Curso de Graduação em Enfermagem antes e durante a pandemia de COVID-19.

\section{Metodologia}

Trata-se de um relato de experiências de mestrandos e doutorandos do Programa de Pós-Graduação em Enfermagem da Universidade Federal de Santa Maria (UFSM), localizada na região sul do Brasil. São descritas as experiências da práxis docente dos autores desde o ano de 2014 até o ano de 2021, acerca do planejamento e desenvolvimento das disciplinas de Exercício A e B contida no Projeto Pedagógico do Curso de Graduação em Enfermagem da instituição, ministradas por meio da Docência Orientada I e II, antes e após a pandemia de COVID-19.

Os discentes stricto sensu desenvolvem atividades de ensino-aprendizagem a partir da apropriação do conteúdo descrito no Projeto Político Pedagógico Institucional (PPPI), no Plano de Desenvolvimento Institucional (PDI) da Universidade e no Projeto Pedagógico do Curso de Enfermagem (PPC), foi elaborado o planejamento pedagógico para as aula, preservando o aspecto formativo e os conteúdos programáticos da disciplina. Inicialmente o plano de trabalho foi construído pelos discentes para posterior aprovação do orientador/professor responsável da disciplina e pelo colegiado do programa de pós graduação (UFSM, 2007). Deste modo, o docente responsável pela disciplina acompanhou não só o planejamento, mas também o desenvolvimento e a avaliação da disciplina, dando o suporte necessário aos discentes stricto sensu.

As disciplinas de "Exercício da Enfermagem A e B" são teóricas e obrigatórias, contêm carga horária de 30 horas semestrais cada e compreendem conteúdos relacionados à ética, bioética e bioética clínica aplicados ao exercício da enfermagem nos diferentes cenários. A disciplina de Exercício da Enfermagem A é ofertada ao $3^{\circ}$ semestre do curso de graduação e apresenta como objetivo conhecer e oportunizar a aplicabilidade de conteúdos de ética e legislação de enfermagem para o exercício da profissão (UFSM, 2016). Os principais conteúdos abordados são ética, bioética, valores, moral, a declaração universal de bioética e direitos humanos, a legislação de enfermagem, direitos dos usuários de saúde e do enfermeiro, sigilo e confidencialidade.

Já a Disciplina de Exercício da Enfermagem B objetiva proporcionar o conhecimento e a reflexão crítica sobre os 
aspectos éticos, bioéticos e legais relacionados ao processo de viver e morrer (UFSM, 2016). A disciplina é ofertada aos discentes que estão cursando o $5^{\circ}$ semestre do curso e apresenta como pré-requisito a aprovação na disciplina Exercício da Enfermagem A. De maneira geral os conteúdos abrangem a história da bioética e bioética clínica, bioética no início da vida humana e no final da vida humana.

Em cada encontro, estratégias metodológicas ativas foram preparadas e utilizadas a fim de incentivar e envolver os estudantes e, assim promover sua autonomia e participação no processo de ensinar e aprender, favorecendo melhor desempenho acadêmico e estimulando, desta forma, a criatividade e o interesse pelos temas abordados. As duas disciplinas possuíam um cronograma de estudos que foi discutido previamente com os discentes. A partir desse, os temas de cada encontro eram abordados com auxílio do planejamento de aula. Esse era utilizado pelos discentes stricto sensu para guiar as discussões e o andamento de cada encontro. Ali abordava-se como seria conduzido o tema, os questionamentos a serem realizados, a construção teórica do conteúdo e a finalização do mesmo, em que procurou-se seguir a proposta de metodologia ativa.

Entretanto, no ano de 2020, o ensino em seus diferentes níveis necessitou adaptar-se ao contexto instaurado pela pandemia da COVID-19. Inicialmente, todas as informações e condutas eram permeadas de incertezas. Conforme os estudos acerca da doença e de sua disseminação iam avançando, a formação profissional precisou adaptar-se em alternativas remotas de ensino. Com isso, os discentes stricto sensu necessitaram planejar as aulas a partir na nova realidade imposta. Para isso, partiu-se do plano já existente e pontuaram-se estratégias que possibilitavam sua adaptação para o ensino remoto.

Inicialmente utilizou-se o E-mail como forma de comunicação com os discentes de graduação, até que fosse estabelecida uma plataforma de apoio padrão definida pelo Instituição de Ensino. Entre as ferramentas utilizadas incluíram-se o google meet, para encontros síncronos, a plataforma classroom com acesso via e-mail institucional de cada discente e docente. Neste, eram postados o planejamento da disciplina, os materiais de apoio para as aulas e as avaliações e ainda, servia como meio de comunicação entre discentes e docentes. As adaptações foram realizadas de acordo com a singularidade das turmas de discentes, considerando suas necessidades.

No processo de ensino-aprendizagem, os docentes são responsáveis pela criação de espaços e oportunidades que possibilitem não apenas a formação de profissionais com capacidade técnica, mas, sobretudo, comprometidos socialmente, o que é um dos objetivos das instituições de ensino superior. Portanto, o docente é também responsável pela construção social dos estudantes, o que demanda proporcionar interações que os levem à reflexão do contexto social, bem como ao desenvolvimento de senso crítico para a resolução dos problemas (Alexandre et al., 2018). Assim, essas metodologias além de contribuir no entusiasmo pelos assuntos, também possibilita aos discentes o desenvolvimento de sua autonomia e reflexão. Entre as diversificadas possibilidades de Metodologias Ativas, utilizaram-se vídeos, filmes, estudos de caso, jogos educativos, portfólios e seminários.

\section{Resultados e Discussão}

Durante cada estágio de docência orientada foi elaborado um planejamento de cada aula, um plano de ensino e um relato com pontos positivos e pontos negativos, assim como apontamentos do que poderia ser melhorado para as próximas aulas. O processo foi acompanhado pelo professor orientador. A inserção dos mestrandos e doutorandos na prática docente oportunizou primeiramente o conhecimento dos pilares que regem as políticas educacionais, por meio do PPPI, PDI e PPC de enfermagem, seguida do planejamento, desenvolvimento e avaliação da disciplina, alicerçados nos conteúdos programáticos, nos recursos de ensino e nos objetivos a serem alcançados.

A discussão de estratégias de ensino aprendizagem também perfez o rol de atividades realizadas. Desse modo tornouse possível contribuir para a formação dos discentes em diferentes atividades, aproximando teoria e realidade, ao mesmo tempo em que promoveu a formação dos discentes stricto sensu. Além disso, ocorreu a observação do trabalho docente na condução 
dos alunos no campo da educação para o cuidado, o qual permite reflexão sobre o componente educativo da prática do enfermeiro.

A formação pedagógica não deve ser entendida como atividade meramente técnica, mas sim como processo complexo reflexivo e criador frente a práxis do ensinar e aprender (Vasquez, 2011). Tal práxis, deve ser percebida como atividade social transformadora de docentes e discentes a medida em que o cotidiano acadêmico permite a estes atores o fortalecimento e entrelaçamentos das unicidades teóricas e práticas da disciplina. O processo formativo como um todo diz respeito ao entendimento das questões pedagógicas e da realidade institucional, das particularidades pessoais e das trajetórias individuais e coletivas entre docentes e discentes.

Nesse sentido, a responsabilidade do professor em ultrapassar as questões relacionadas a formação profissional é essencial, devendo estar atento a formação de sujeitos éticos e comprometidos socialmente. Nesse contexto, a docência universitária exige, além de conhecimentos específicos sobre sua área de formação, que o docente atue sobre fundamentos pedagógicos do processo de ensino-aprendizagem, aliados aos saberes de sua experiência e de sua produção científica. É uma atividade que demanda preparo e dedicação do docente, o qual precisa oferecer ferramentas que motivem discentes ao aprendizado (Junges, \& Behrens, 2016).

O profissional de Enfermagem deve atuar com autonomia e em consonância com os preceitos éticos e legais, técnicocientífico e teórico-filosófico; exercer suas atividades com competência para promoção do ser humano na sua integralidade, de acordo com os Princípios da Ética e da Bioética (COFEN, 2017). Tendo em vista a atuação profissional, pautada em princípios Éticos e Bioéticos, as disciplinas "Exercício da Enfermagem A e B" visam preparar os discentes para trabalhar de maneira legal, responsável e prudente frente aos conflitos morais surgidos na prática assistencial, tanto nas relações com os pacientes, familiares e equipe de trabalho.

Para a elaboração de novas propostas pedagógicas, os cursos de graduação e com destaque os da área da saúde, têm sido estimulados a incluírem, em suas reorganizações, metodologias de ensino que permitam dar conta dos novos perfis profissionais. Em virtude deste ressignificar de conceitos e valores, as Instituições de Ensino Superior têm lançado mão do que convencionou-se denominar de Metodologias Ativas. Encontramos em Paulo Freire (1986), uma defesa para as metodologias ativas, com sua afirmação de que na educação de adultos, o que impulsiona a aprendizagem é a superação de desafios, a resolução de problemas e a construção do conhecimento novo a partir de conhecimentos e experiências prévias dos indivíduos (Freire, 1986).

Quando começamos a observar e tentar compreender como o processo de ensinar e aprender ocorre, observamos que a situação pode ocorrer de maneiras múltiplas (Funai, Filho, Maestri, \& Martini, 2016). As metodologias ativas fazem uso da problematização como estratégia de ensino/aprendizagem, com o objetivo de alcançar e motivar o discente, pois, diante do problema, ele se apreende, examina, reflete, correlaciona a sua história e passa a ressignificar suas descobertas. Ainda, a problematização pode guiar o aluno ao contato com as informações e à produção do conhecimento, principalmente, com a finalidade de solucionar os impasses e promover o seu próprio desenvolvimento.

É imprescindível que o docente de enfermagem, com o intuito de promover melhorias na formação dos acadêmicos, se aproprie de um método pedagógico coerente e eficaz para o processo de ensino aprendizagem. Nesse sentido, o planejamento de aula é uma ferramenta fundamental para que os objetivos propostos para uma disciplina sejam alcançados. Planejar possibilita antecipar o que pode acontecer, de modo que o docente se prepara para os possíveis caminhos que a atividade poderá percorrer (Mortimer, \& Scott, 2016).

Assim, o plano de ensino e o desenvolvimento dos materiais foram de responsabilidade dos discentes de mestrado/doutorado, todos elaborados previamente e discutidos com a docente orientadora. Cabe-se ressaltar que durante o exercício da docência, o planejamento de ensino foi adequado conforme a necessidade dos discentes. De acordo com Vázquez 
(2011), não basta que a atividade docente seja intencional e planejada, pois assim o professor não cumpriria seu papel de agente social de mudança que, ao transformar uma dada realidade, transforma a si próprio e aos outros. É necessária a mudança e adequação conforme a necessidade dos atores sociais envolvidos.

Em sequência, na fase de execução do plano de ensino a docente responsável pela disciplina fez-se presente em tempo integral, dando o suporte necessário para o planejamento e desenvolvimento das aulas; bem como o acompanhamento da evolução das discentes de mestrado nas práxis da docência. Porém, mesmo com o aporte do docente compreende-se que o discente de pós-graduação precisa assumir responsabilidades junto ao grupo em que está desenvolvendo o seu trabalho, tornando a educação prazerosa e significativa para todos os envolvidos nesse processo.

Repensar novas práticas de ensino e aprendizagem na educação superior é um desafio para os docentes do curso de Enfermagem no que tange a reorganização de seus planos de ensino para que possam atingir o objetivo da educação remota e inclusão de ferramentas tecnológicas (Silveira A., et al, 2020). A adequação de conteúdo e práticas pedagógicas ao ensino remoto, a adaptação da rotina laboral às atividades do cotidiano familiar, viabilizaram a aquisição de novas competências profissionais e uma integração maior das tecnologias digitais no processo ensino-aprendizagem (Araújo et al., 2021). Com isso, ainda que tenha apresentado-se como um desafio aos discentes stricto sensu, possibilitou aos mesmos experiências ímpares em sua formação docente.

Em conjunto com a professora responsável pela disciplina, mestrandos e doutorandos utilizaram táticas para fomentar a participação dos alunos em atividades como, realização de dinâmicas em grupo, trabalhos em equipe, leitura e discussão de textos, debates durante as aulas, bem como assistir vídeos, elaborar e expor atividades lúdicas. Essas habilidades fazem referência ao conceito de saber ouvir e comunicar-se de forma clara e objetiva como mediador do conhecimento e não como um detentor deste. As metodologias utilizadas foram de aula expositiva dialogada e buscou-se a utilização de metodologias ativas.

A aula expositiva dialogada configura-se como uma exposição de conceitos, com a colaboração ativa dos discentes, assim o conhecimento prévio do discente é de extrema importância, devendo ser considerado este o ponto de partida. O docente tem o papel de incentivar os discentes a refletirem, questionarem, discutirem, interpretarem o objeto de estudo e, o diálogo deve ser a principal estratégia, propiciando a análise crítica, a produção de novos conhecimentos e o desencadeamento de um olhar crítico (Lopes, 2012).

Ao abordarem essa questão, Freire e Shor evidenciam o valor que a aula expositiva, desde que dialogada, possui. Nem toda aula expositiva é por si só um exemplar de um tradicionalismo pedagógico. Ao contrário, uma aula expositiva interativa e dinâmica, calcada no diálogo, é algo, nos dizeres freirianos, com potencial libertador (Freire \& Shor, 1986).

As Metodologias Ativas, de acordo com Berbel (2014) "baseiam-se em formas de desenvolver o processo de aprender, utilizando experiências reais ou simuladas, visando às condições de solucionar, com sucesso, desafios advindos das atividades essenciais da prática social, em diferentes contextos". Por exemplo: estudos clínicos, jogos lúdicos, portfólios, seminários e, realização de pesquisas extra classe. Também, foi estendido o convite para profissionais de referência abordarem temáticas específicas (captação e doação de órgãos, diretivas antecipadas de vontade) com vistas a aproximar o saber do fazer em enfermagem nos diferentes cenários. Destaca-se que para que as práticas de ensino remoto possam acontecer é necessário que o docente às construa de forma atrativa, a fim de despertar motivação, logo, adesão discente nas atividades propostas. Além disso, precisa ser organizada de maneira flexível e acessível referente ao acesso à internet domiciliar e aos dispositivos utilizados (Silveira et al., 2020).

A organização da aula, partindo da prática social do discente e docente, representa a valorização da percepção que estes trazem sobre o tema de estudo. A partir de suas experiências e sua prática social, ao ser problematizada, possibilita ao docente construir novas sínteses e reelaborá-las. 
Nenhum material didático pode, por melhor elaborado que seja, garantir por si só a qualidade e a efetividade, quer do ensino quer da aprendizagem (Rangel, 2002). De acordo com o autor, a seleção adequada desses materiais depende de três critérios de escolha que compreendem o sujeito envolvido, os objetivos visados e a situação que envolve espaços, equipamentos e recursos humanos. Assim, para auxiliar no desenvolvimento das metodologias ativas, de acordo com o conteúdo a ser abordado, entre os materiais didáticos foram utilizados: slides em power point com uso de retroprojetor; cópias de capítulos de livros e de artigos científicos, filmes, vídeos, casos clínicos, notícias, materiais para confecção de cartazes, portfólios e jogos interativos (jogos de verdade ou mito, jogo de tabuleiro, show do milhão, encenação de júri, quiz, perguntas e respostas).

Para o exercício desta práxis docente, o diálogo se configurou como princípio orientador, como forma de abertura ao outro em busca de questionamentos e reflexões ao problematizar questões específicas a cada assunto. A abertura ao diálogo e a sensibilidade do docente são elementos importantes na constituição da relação pedagógica em sala de aula. O diálogo promove "a experiência da abertura como experiência fundante do ser inacabado que terminou por se saber inacabado" (Freire, 1996).

Os docentes de enfermagem são reconhecidos pelo seu comprometimento no uso e aplicabilidade no campo das novas tendências pedagógicas. Mesmo diante da realidade de utilização de diferentes tecnologias de comunicação aplicadas à educação como computador e/ou projetor, as aulas expositivas ainda são as mais utilizadas pelos docentes, mesmo sendo uma das mais defasadas formas de ensino (Rolt et al., 2014).

As aulas expositivas podem se caracterizar como lúdicas e propiciar o processo crítico e criativo do discente, para isso o posicionamento do docente em sala de aula é de extrema importância. O posicionamento do docente influencia no tipo e profundidade da reflexão que o discente pode desenvolver acerca do objeto de estudo.

No que se refere a avaliação, considerando que esta não se dá num vazio e é parte integrante do processo de ensino e aprendizagem efetivado dentro das instituições de ensino, ao analisar a questão da avaliação da aprendizagem é necessário considerar a categoria da totalidade, inserindo-a num contexto mais amplo, pois a natureza de seu processamento e de seus resultados está em estreita relação com variáveis contextuais: educação e sociedade, contexto social, político e econômico. É fundamental levar em conta o papel das variáveis contextuais no processo ensino/aprendizagem assim como na avaliação. Desse modo, a sua abordagem qualitativa pode dar conta de abarcar essas variáveis sob um enfoque que contribua para a reconstrução social. Isso significa que a avaliação, para além de dados quantitativos e classificatórios, deve considerar a multiplicidade de fatores que contribuem para proporcionar informações sobre os processos de aprendizagem e as dificuldades vividas pelos discentes (Cária, \& Paiva, 2018).

A avaliação da aprendizagem constitui-se em importante ferramenta, tanto para o diagnóstico do processo de aprendizagem, como para fornecer as bases de potencialização deste, caracteriza-se enquanto atividade permanente e indissociável do processo ensino-aprendizagem, e ocorreu durante todo o andamento das disciplinas realizadas durante a docência orientada. Deste modo, foram consideradas a presença, participação nas atividades e discussões realizadas em sala de aula, realização e entrega de sínteses e trabalhos solicitados e a realizadas de avaliações teóricas, abrangendo todos os conteúdos abordados, bem como, a criatividade frente a elaboração dos seminários e construção do portfólio das disciplinas.

Ao final de cada aula os discentes eram convidados a avaliar o desenvolvimento das atividades, propiciando melhorias quanto as metodologias utilizadas, recursos didáticos e, postura docente. Também, os discentes de graduação realizaram uma avaliação individual por meio de instrumento contendo questões não só acerca dos conteúdos abordados e das metodologias desenvolvidos em aula, mas também acerca dos docentes que a desenvolveram, em especial mestrados e doutorandos. Essa avaliação fez-se relevante e necessária para conhecer a percepção dos graduandos sobre o processo de ensino-aprendizagem, além de avaliar se as metodologias adotadas e a postura dos discentes stricto sensu foram satisfatórias.

Os momentos de socialização oportunizados ao longo das disciplinas promoveram sentimentos individuais e 
coletivos, contribuindo para o processo de construção do conhecimento dos envolvidos (docentes e discentes). Assim, a vivencia da docência orientada pelos pós graduandos, proporciona oportunidades ímpares de experienciar a prática do ensino, desde o planejamento das atividades de forma ativa, reflexiva e criativa, até a sua execução, permitindo aos discentes stricto sensu, perceber e avaliar diferentes estratégias aplicadas no processo seu ensino-aprendizagem (Brehmer, \& Ramos, 2014).

A formação pedagógica apresenta-se como elemento fundamental para a identificação com a profissão professor; e para o fortalecimento docente no enfrentamento das suas fragilidades (Fernandes, \& Souza, 2017). Para tanto, o preparo frente a diversas complexidades que envolvem o educar e o formar profissionais no ensino superior são indispensáveis na formação de cientistas e docentes (Pereira et al, 2021). Destaca-se que ao longo do desenvolvimento das disciplinas a docente responsável propiciou momentos de diálogo para discutir e pontuar as fragilidades e potencialidade identificadas, visando o desenvolvimento e aperfeiçoamento dos discentes stricto sensu na formação docente.

Além do desafio de incluir o discente no ensino e aprendizagem remotos, há um desafio do docente nesse processo, pelo fato de se permitir a novas habilidades relacionadas às ferramentas tecnológicas, as quais se mostram menos desafiadoras aos discentes (Silveira et al., 2020). Destaca-se que o cuidado de enfermagem é presencial e indispensável. Assim, a formação de profissionais para cuidar de vidas humanas requer conhecimentos, habilidades e atitudes na integração ensino serviçocomunidade e no trabalho interprofissional (Lira et al., 2020). Com isso, os discentes stricto sensu além de adentrar ao mundo das tecnologias educacionais, ainda necessitaram manter a sensibilidade e a coerência na formação de profissionais que prestarão assistência e cuidados a outras vidas humanas.

\section{Considerações Finais}

A docência orientada caracteriza-se como momento único na formação docente que oportuniza o exercício prático do "ser docente", apresentando influências para a formação de mestres e doutores em enfermagem. A orientação por um docente experiente apresenta-se como modelo e suporte aos aprendizes, por meio da interação, compartilhamento, sugestões e incentivos. A educação para o futuro carece que o papel do professor esteja voltado para uma prática que considere a autonomia dos sujeitos, o senso crítico, a (co)responsabilização. Por meio do desenvolvimento da docência orientada nas disciplinas teóricas de Exercício da Enfermagem A e B foi possível compreender a importância do docente no processo de ensinar e aprender, além de compreender sua atuação na formação de enfermeiros éticos, conscientes e comprometidos com a construção e consolidação do saber e fazer da disciplina.

Essas atividades foram essenciais para a formação de docentes, visto que o exercício da docência possibilita com que o discente da Pós-Graduação exercite e reflita acerca do planejamento e condução de atividades de cunho teórico-práticas. Em especial, diante da emergência educacional durante a pandemia, houve a necessidade de adaptação de docentes e discentes no novo cenário de ensino remoto. Desta forma, os docentes em formação também precisaram adaptar-se à nova realidade, lançando mão de estratégias de ensino alicerçadas a diferentes tecnologias que possibilitassem a continuidade do ensino na graduação em enfermagem, bem como de sua própria formação.

Diante disso, a práxis da docência orientada foi de grande relevância para o crescimento dos mestrandos e doutorandos no que se refere a postura, planejamento, pensamento crítico e reflexivo e tomada de decisão e possibilidades de reinventar as formas de ensino no decorrer do exercício da docência. A introdução de estratégias metodológicas ativas de ensino, técnicas e instrumentos inovadores contribuiu com a qualidade do processo de ensino-aprendizagem e favoreceu o aprender e a produção de conhecimentos.

No que tange à prática docente, este relato de experiência reforça a importância de que a formação de mestrandos e doutorando possibilite a prática da docência. Com isso, a formação docente torna-se qualificada, na medida em que o orientador viabiliza o processo de ensino e aprendizagem, compartilhando também sua experiência e seus conhecimentos da 
trajetória docente.

\section{Referências}

Araújo A. R. L., Sousa L. M. C., Carvalho R. B. S., Oliveira A. D. S., Amorim F. C. M., Sousa K. H. J. F., Zeitoune R. C. G., Damasceno C. K. C. S. (2021). O trabalho remoto de enfermeiros docentes em tempos de Pandemia. Esc Anna Nery;25(spe): e20210198. https://doi.org/10.1590/2177-9465-EAN-2021-0198

Alexandre, K. C. R. S., \& Werneck, A. L., Chainça, E., Cesarino, C. B. (2018). Docência em cursos superiores de enfermagem: formação e práticas pedagógicas. Revista Baiana de Enfermagem, Bahia, Brasil.

Bastolla, F. F., Da Silva, L. R., De Souza, A. E., \& Lauxen, S. L. (2017). A Docência no Ensino Superior: reflexões sobre a prática da produção de textos na perspectiva da retórica. Revista do Programa de Pós-Graduação em Práticas Socioculturais e Desenvolvimento Social, Cruz Alta, RS, Brasil.

Berbel, N. A. N. (2014). Metodologia da problematização: respostas de lições extraídas da prática. Semina: Ciências Sociais e Humanas (Online), Londrina, PR, Brasil.

Brasil. Ministério da Saúde. (2020 a). Portaria nº 188, de 03 de fevereiro de 2020. Declara Emergência em Saúde Pública de importância Nacional (ESPIN) em decorrência da Infecção Humana pelo novo Coronavírus (2019-nCoV). Diário oficial da União. 04 fev 2020; Seção: 1:1.

Brasil. Ministério da Saúde. (2020 b). Portaria n ${ }^{\circ}$ 454, de 20 de março de 2020. Declara, em todo o território nacional, o estado de transmissão comunitária do coronavírus (covid-19). Diário oficial da União. 20 mar 2020; Seção: 1:1.

Brehmer, L. C. F., \& Ramos, F. R. S. (2014). Experiências de integração ensino-serviço no processo de formação profissional em saúde: revisão integrativa. Revista Eletrônica de Enfermagem, Goiânia, GO, Brasil.

Cária, N. P., \& Paiva, E. C. (2018). Avaliação da aprendizagem na educação superior versus avaliação do desempenho. Revista de ciências humanas, Frederico Westphalen, RS, Brasil.

Resolução COFEN N ${ }^{\circ}$ 564/2017. Aprova o novo Código de Ética dos Profissionais de Enfermagem. Brasília, Brasil. http://www.cofen.gov.br/resolucao-cofenno-5642017_59145.htm.

Fernandes, C. N. S., \& Souza, M. C. B. M. (2017). Docência no ensino superior em enfermagem e constituição identitária: ingresso, trajetória e permanência. Revista Gaúcha Enfermagem, Porto Alegre, RS, Brasil. http://www.scielo.br/pdf/rgenf/v38n1/0102-6933-rgenf-1983-144720170164495.pdf.

Freire, P., \& Shor, I. (1986). Medo e ousadia - o cotidiano do professor. Paz e Terra.

Freire, P. (1986). Educação como Prática da Liberdade (17a ed.). Paz e Terra.

Freire, P. (1996). Pedagogia da autonomia: saberes necessários à prática educativa. Paz e Terra.

Funai, A., Filho, C. C. S., Maestri, E., \& Martini, J. G. (2016). Saberes necessários à prática educativa: ensinar é uma especificidade humana (p. 99-117). In: Prado, M.L., Reibnitz, K.S. Paulo Freire: a boniteza de ensinar e aprender na saúde. NFR/UFSC: Florianópolis, SC, Brasil.

Portaria $n^{\circ}$ 181, de 18 de dezembro de 2012. Regulamento de suporte à Pós-Graduação de Instituições de Ensino Particulares - PROSUP. https://www.capes.gov.br/images/stories/download/legislacao/Portaria_181_de-18122012.pdf

Junges, K. S., \& Behrens, M. A. (2016). Prática docente no Ensino Superior: a formação pedagógica como mobilizadora de mudança. Revista Perspectiva, Erechim, RS, Brasil.

Leitão, V. R., Passerino, L. R. M., \& Wachowicz, L. A. (2017). Novos Tempos, Novas Práticas...repensando metodologia e avaliação no Ensino Superior: Relato de Pesquisa. Revista Diálogo Educacional, Curitiba, PR, Brasil.

Lira A. L. B. C., Adamy E. K., Teixeira E., \& Silva F. V. (2020). Nursing education: challenges and perspectives in times of the COVID-19 pandemic. Rev Bras Enferm; 73(Suppl 2):e20200683. http://dx.doi.org/10.1590/0034-7167-2020-0683

Lopes, T. O. (2012). Aula expositiva dialogada e aula simulada: comparação entre estratégias de ensino na graduação em enfermagem (Dissertação de mestrado). Universidade de São Paulo, Escola de Enfermagem da Universidade de São Paulo, SP, Brasil.

Mesquita, S. K. C., Meneses, R. M. V., \& Ramos, D. K. R. (2016). Metodologias ativas de ensino/aprendizagem: dificuldades de docentes de um curso de enfermagem. Trab. Educ. Saúde. Rio de Janeiro, RJ, Brasil. http://www.scielo.br/pdf/tes/v14n2/1678-1007-tes-1981-7746-sip00114.pdf.

Mortimer, E. F., \& Scott, P. (2016). Atividade discursiva nas salas de aula de ciências: uma ferramenta sociocultural para analisar e planejar o ensino. Investigações em Ensino de ciências, Porto Alegre, RS, Brasil.

Pereira, S. L. M., Fernandes, D. de S., Silveira, T. L. S., Miasso, A. I., Rodrigues, R. A. P., \& Pillon, S. C. (2021). Desafios para a práxis do docente em Enfermagem no Ensino Superior. Research, Society and Development, 10(4), e24910412534. https://doi.org/10.33448/rsd-v10i4.12534

Rangel, E. O. (2002). Sobre sujeitos, situações e materiais didáticos no processo de ensino-aprendizagem. Boletim- PGM 1 Materiais Pedagógicos, São Paulo, SP, Brasil. http://www.tvebrasil.com.br/SALTO/boletins2002/mp/tetxt1.htm

Rolt, V. A., Bartolloto, E., \& Dallabona, K. G. (2014). A utilização de metodologias diferenciadas no ensino de ciências e biologia em duas escolas da rede pública do município de Criciúma. Maiêutica: curso de ciências biológicas, Brasil.

Silva F. O. et al. (2021). Experiência em aulas remotas no contexto da pandemia da COVID-19. Rev enferm UFPE on line.;15: e247581. 10.5205/19818963.2021.247581 https://periodicos.ufpe.br/revistas/revistaenfermagem 
Research, Society and Development, v. 10, n. 16, e541101624023, 2021

(CC BY 4.0) | ISSN 2525-3409 | DOI: http://dx.doi.org/10.33448/rsd-v10i16.24023

Universidade Federal de Santa Maria. (2016). Currículo do Curso de enfermagem. Ementários disciplina de Exercício da Enfermagem A. em:https://portal.ufsm.br/ementario/disciplina.html?idisciplina=86909.

Universidade Federal de Santa Maria. (2016). Currículo do Curso de enfermagem. Ementários disciplina de Exercício da Enfermagem B. https://portal.ufsm.br/ementario/disciplina.html?idDisciplina=86913.

Universidade Federal de Santa Maria. (2007). Ementário do Programa de Pós-Graduação em Enfermagem na modalidade de Mestrado. Atividades Curriculares obrigatórias: Docência orientada. http://coral.ufsm.br/ppgenf/images/Mestrado/Disciplinas/Docencia_orientada_I.pdf.

Varella T. C. M. L. et al. (2020). Graduação em Enfermagem em Tempos da Covid-19: Reflexões sobre o Ensino Mediado por Tecnologia. EaD em Foco; 10(3): e119. https://doi.org/10.18264/eadf.v10i3.1194

Vasconcello, M. M. M., \& Sordi, M. R. L. Formar professores universitários: tarefa (im)possível? Interface 20(57): 403-14. http://www.scielo.br/pdf/icse/v20n57/1807-5762-icse-1807-576220150450.pdf.

Vázquez, A. S. (2011). Filosofia da práxis. (2a ed.), Expressão Popular. 